\title{
Fifty Years of Magnetic Fusion Research (1958-2008): Brief Historical Overview and Discussion of Future Trends
}

\author{
Laila A. El-Guebaly \\ University of Wisconsin-Madison, 1500 Engineering Dr. Madison, WI 53706, USA; \\ E-Mail: elguebaly@engr.wisc.edu; Tel.: +01-608-263-1623; Fax: +01-608-263-4499
}

Received: 3 March 2010; in revised form: 29 April 2010 / Accepted: 10 May 2010 /

Published: 1 June 2010

\begin{abstract}
Fifty years ago, the secrecy surrounding magnetically controlled thermonuclear fusion had been lifted allowing researchers to freely share technical results and discuss the challenges of harnessing fusion power. There were only four magnetic confinement fusion concepts pursued internationally: tokamak, stellarator, pinch, and mirror. Since the early 1970s, numerous fusion designs have been developed for the four original and three new approaches: spherical torus, field-reversed configuration, and spheromak. At present, the tokamak is regarded worldwide as the most viable candidate to demonstrate fusion energy generation. Numerous power plant studies $(>50)$, extensive R\&D programs, more than 100 operating experiments, and an impressive international collaboration led to the current wealth of fusion information and understanding. As a result, fusion promises to be a major part of the energy mix in the $21^{\text {st }}$ century. The fusion roadmaps developed to date take different approaches, depending on the anticipated power plant concept and the degree of extrapolation beyond ITER. Several Demos with differing approaches will be built in the US, EU, Japan, China, Russia, Korea, India, and other countries to cover the wide range of near-term and advanced fusion systems.
\end{abstract}

Keywords: fusion history; magnetic fusion concepts; power plants designs

\section{Brief Historical Overview}

Even though the American scientist Langmuir first discovered the plasma (a collection of charged particles; meaning "moldable substance" in Greek) in 1929, fusion was not pursued as a potential source of energy until the early 1950s. Today, fusion is the most significant application of plasma. After the 1956 sensational report by I.V. Kurchatov (at the Harwell campus in England) on the 
possibility of thermonuclear reactions in gaseous discharge, 105 papers on plasma physics and controlled thermonuclear fusion were submitted to the 1958 2nd Conference on the Peaceful Uses of Atomic Energy held by the United Nations in Geneva, Switzerland. During the early 1950s, the major nuclear power countries at that time (Soviet Union, UK, and US) were actively involved in the fusion research field. Before the conference, they declassified their fusion research, allowing researchers around the world to discuss the challenges of fusion as a new source of energy [1]. Since then, fusion research programs in many nations, supported by strong international cooperation, have led to outstanding progress towards the development of magnetic fusion. At present, there are $>100$ operating experimental facilities, more than 50 power plant studies, and extensive research and development (R\&D) programs around the globe. As a result, fusion promises to be a major part of the energy mix in the $21^{\text {st }}$ century and beyond.

Only four magnetic confinement concepts were pursued internationally in the 1950s: tokamak, stellarator, pinch, and mirror. These concepts experienced substantial modifications over the past five decades. Beginning in the late 1960s and continuing to the present, more than 50 conceptual power plant design studies have been conducted worldwide, covering a wide range of new and old design approaches of toroidal configurations [tokamak, stellarator, spherical torus (ST), reversed-field pinch (RFP), and spheromak] and linear systems [field-reversed configuration (FRC) and tandem mirror (TM)]. Most studies and experimental devices employed the D-T fuel cycle, since it has the least demanding physics conditions to reach ignition. The stress on fusion safety has stimulated worldwide research on fuel cycles other than D-T that would produce much fewer neutrons. These advanced fuels are based on 'advanced' reactions, such as deuterium-deuterium (D-D), deuterium-helium-3 (D- ${ }^{3} \mathrm{He}$ ), proton-boron-11 ( $\left.\mathrm{p}^{-1} \mathrm{~B}\right)$, and ${ }^{3} \mathrm{He}-{ }^{3} \mathrm{He}$. The chief downside of these cycles is the more difficult physics requirements to reach ignition.

Numerous experiments and conceptual power plant designs have been developed for all seven confinement approaches, especially the tokamak [2]. Over the past 50 years, the main progress in fusion research has been directly connected to the construction of large experimental facilities with copper and/or superconducting magnets (T-3, TFTR, JT-60U, JET, Tore Supra, etc.), achievement of power plant-relevant parameters in tokamak and non-tokamak experiments, steady-state operation for a limited time (few hours), suppression of plasma instabilities, and discovery of new plasma operating modes with enhanced confinement regimes. In the mean time, the power plant studies remained an essential element of the fusion development process in order to understand the future trends. Basically, these studies help the fusion community identify the major physics and technology problems and provide guidance for the R\&D program to deliver a viable end product. Figure 1 displays the timeline of the 58 large-scale magnetic fusion power plants designed since the early 1970s by research teams in the US and abroad [3]. In the US, the decade of the 1980s witnessed a transition period aimed at temporarily reducing the emphasis on the large-scale tokamak studies in order to investigate several alternate concepts: stellarator, ST, RFP, spheromaks, FRC, and TM. Due to budgetary constraints, the US had decided in the late 1980 s to pursue all confinement concepts, except tandem mirrors. 
Figure 1. Timeline of large-scale conceptual power plant designs developed in the US (38-unmarked) and abroad (20-marked) for magnetic fusion [3].

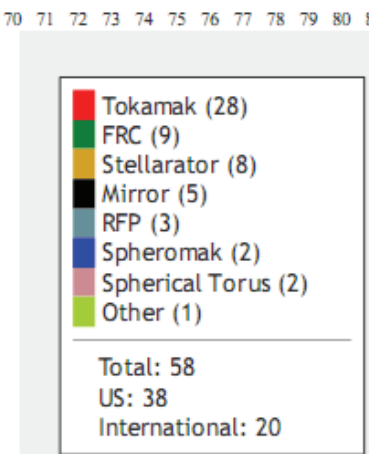

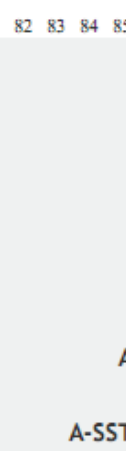

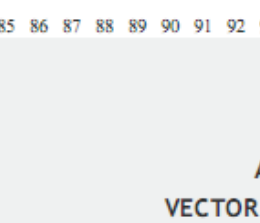

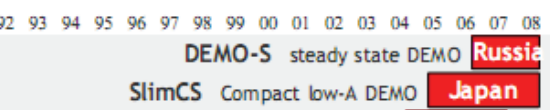

FDS-II China power plant China

ARIES-CS Compact Stellarator (UCSD)

VECTOR VEry Compact TOkamak Reactor Japan

DEMO2001 Japar

PPCS Conceptual Study of Fusion Power Plants EU

ARIES-AT Advanced Tokamak (UCSD)

APEX-FRC pulsed liquid walled power plant (UCLA)

RF/UW-FRC D-3He fuelled power plant Russia

A-SSTR2 Combine advantages of A-SSTR and DREAM Japan

HSR Helias Stellarator Reactor

UK-ST conceptual design

UW-FRC UW-FRC power plant (UW)

ARIES-ST SphericalTorus (UCSD)

ARIES-RS Reversed-Shear tokamak (UCSD)

A-SSTR Advanced Steady State Tokamak Japa

FFHR Force Free Helical Reactor

DREAM Drastically Easy Maintenance Tokamak

CREST Compact Reversed Shear Tokamak Japar

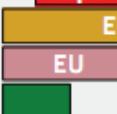

EU

U

ШNL Spheromak advanced spheromak fusion reactor
SPPS Stellarator Power Plant Study (UCSD)

SEAFP Safety and Environmental Assessment of Fusion Power

PULSAR-I/II pulsed tokamak (UCSD)

ARIES-IV Second-stability tokamak (UCLA)

ARIES-II Second-stability tokamak (UCLA)

ARIES-III D-3He-fuelled tokamak (UCLA)

Japan SSTR steady state tokamak

Japan ARTEMIS D-3He fuelled FRC power plant

ARIES-I First-stability tokamak (UCLA)

Apollo D-3He Fuelled Tokamak (UW)

Japan Ruby D-3He FRC reactor study

Ra D-3He Fuelled Tandem Mirror (UW)

TITAN reversed-field pinch (UCLA)

ASRA6C Advanced Stellarator Reactor (UW/FRG)

MINIMARS Compact Mirror Advanced Reactor Study (LLNL)

FIREBIRD pulsed FRC power plant (U. Washington)

MARS Mirror Advanced Reactor Study (LLNL)

Spheromak steady state spheromak (LANL)

CRFPR Compact Reversed Field Pinch Reactor (LANL)

UWTOR-M Modular Stellarator Power Reactor (UW)

Russia RT

RT reactor torsatron

Wildcat catatyzed D-D tokamak (ANL)

MSR Modular Stellarator Reactor (LANL)

EBTR Elmo Bumpy Torus Reactor Conceptual Design Study (ORNL)

RFPR Reversed Field Pinch Reactor (LANL)

WITAMIR-I Wisconsin Tandem Mirror (UW)

FRC Compact fusion reactor (LANL)

TRACT FRC fusion reactor study (MSNW)

STARFIRE Commercial Tokamak Fusion Power Plant (ANL)

NUWMAK University of Wisconsin Tokamak (UW)

SAFFIRE D-3He fuelled FRC design (UIUC)

Russia TVE-2500 high temperature power plant with direct conversion

UWMAK-III University of Wisconsin Tokamak (UW)

UWMAK-II University of Wisconsin Tokamak (UW)

A Fusion Power Plant (PPPL)

UWMAK-I University of Wisconsin Tokamak (UW)

Premak University of Wisconsin Tokamak (UW)

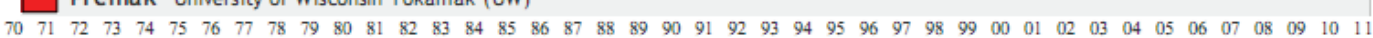

calendar year 


\section{Main Features of Attractive Power Plants}

A number of basic features are likely to be present in the $10^{\text {th }}$-of-a-kind commercial power plant. Firstly, high power density machines are compact and provide many positive attributes, but require advanced physics (such as high beta-ratio of plasma pressure to magnetic field pressure), coupled with advanced technology: an innovative first wall design that operates with $>5 \mathrm{MW} / \mathrm{m}^{2}$ neutron wall loading (NWL), advanced divertor system that can withstand $>10 \mathrm{MW} / \mathrm{m}^{2}$ heat flux, radiation-resistant low-activation structural materials that can handle $>200$ displacements per atom, and high field magnets that can provide $\geq 16 \mathrm{~T}$. Secondly, commercial plants will operate in steady-state mode to eliminate the cyclic fatigue and the need for an energy storage system. Thirdly, the plant should operate successfully for 50 years or more with regular replacements of inner power core components (every 3-5 years), while outer power core components operate reliably for the entire plant lifetime.

In most designs, the magnets are protected from the energetic neutrons by the in-vessel components: blanket, shield, and vacuum vessel. The blanket contains lithium compounds to breed tritium for D-T fuelled cycles. In addition, the blanket and other power core components convert the nuclear energy into thermal energy that is transferred to the thermal/electrical conversion system. The external heat transfer system must be able to efficiently handle high temperature heat transfer media (700-1100 $\left.{ }^{\circ} \mathrm{C}\right)$ in concert with advanced energy conversion concepts. The challenging fusion environment (14.1 MeV neutrons, high heat flux, thermo-mechanical stresses, and chemical compatibility issues) mandates employing low-activation, radiation resistant structural materials (such as advanced ferritic steels, vanadium alloys, and/or SiC/SiC composites) to assure the successful development of economical fusion energy. Fusion materials should contain benign alloying elements and an extremely low level of impurities to produce only low-level waste and allow recycling and clearance of all fusion components.

To date, the fusion physics has progressed significantly for all concepts. Since the majority of fusion challenges can be tackled with well-coordinated international effort, the world fusion community formed unique international scientific and engineering teams in the 1980 s to develop the INternational TOkamak Reactor (INTOR) design [4,5]. Even though INTOR was designed in great detail, it was never built, but the international activities continued to date along the same line. The most recent international activities led to the construction of ITER [6]. It is designed with currently available materials and present technologies and based on experimental data and theoretical studies performed over the past few decades. As expected, ITER will advance the knowledge database for tokamak physics and technology further. However, much more R\&D is required in the technology area of fusion power plants (materials; blanket, divertor, and magnet performance; safety assurance; maintenance verification; and advanced power handling). Additional theoretical and experimental research will certainly continue at the domestic and international levels to resolve emerging physics and technology issues necessary to produce viable fusion power plants for all confinements concepts.

\section{Magnetic Fusion Concepts}

This section focuses on the engineering aspects of all seven magnetic concepts developed to date and their evolution to address the basic issues and concerns for fusion science and technology. The majority of the large-scale US power plant designs along with the most recent international (non-US) 
designs are covered briefly. Also, some of the early generations of fusion power plants are mentioned for undertaking noteworthy work. The reader is directed to References 7-13 for additional reviews of fusion physics and technology research.

\subsection{Original Concepts: Tokamak, Stellarator, Pinch, and Mirror}

Tokamak: Currently regarded as the most viable candidate to demonstrate fusion energy generation. Its research dominates the fusion program, accounting for over $90 \%$ of the worldwide magnetic fusion effort. Historically, the tokamak was invented by Russian physicists Sakharov and Tamm in 1951 and the first tokamak experiment began to operate at the Kurchatov Institute (then LIPAN) in Moscow in 1954 [1]. Ever since, the tokamak physics has been successfully demonstrated with more than 100 worldwide experimental facilities, of which $\sim 35$ experiments are operational in several countries [14]. In the late 1980s, the international collaborative effort materialized in the design and construction of ITER [6]-the largest burning plasma experiment, producing 500 MW of fusion power with first plasma expected around 2020.

All tokamaks employ divertors (or limiters) either in single or double null configurations. Large sets of planar toroidal field (TF) and poloidal field (PF) coils confine the plasma. Other coils are necessary to shape and position the plasma within a toroidal vessel of D-shape cross section. The plasma conditions can be sustained by external energy sources (as in existing fusion experiments) or by self-heating of alpha particles produced by fusion reactions, forming burning plasma conditions as in future commercial power plants.

Since the early 1970s, 24 conceptual power plant studies were developed for D-T fuelled tokamaks. These studies progressed steadily from the 1970 pulsed UWMAK series [15] and TVE-2500 [16], to the 1980 STARFIRE [17] (that first promoted steady-state current drive), to the more advanced 1990s steady-state ARIES series [18]. The 1970s US designs uncovered undesirable aspects of pulsed operation and low power density machines, plasma impurity control problems, and maintainability issues. More in-depth power plant studies were initiated in the 1980s in the US and abroad to identify and resolve the physics and technology challenges of tokamaks. Figures 2 and 3 display the tokamak timeline and some features of selected US and non-US conceptual designs. In the 1980s, the US temporarily impeded the large-scale tokamak studies to investigate several alternate concepts (refer to Figure 1). The tokamak studies were resumed in the early 1990s by the ARIES team, delivering a series of advanced tokamak power plants: ARIES-I [19], ARIES-II and ARIES-IV [20], ARIES-RS [21], and ARIES-AT [22]. Improvements were apparent in all designs, progressing from ARIES-I to ARIES-AT. The ARIES design process considered the constructability, fabricability, operability, and maintainability of the plant. The tokamak physics and engineering proceeded interactively while the ARIES systems code determined the reference parameters to optimize the cost of electricity (COE). Noteworthy is that the US is highly motivated to obtain a fusion power plant that is as economically competitive as other energy sources.

Europe, Russia, Japan and China carried out a number of tokamak fusion power plant studies outlined in Figure 3. EU and Japan placed less emphasis on the COE. Their view is that fusion will enter the energy market because of the safety and environmental advantages and large fuel reserve, even if it produces electricity at a somewhat higher cost. In the 1990s, EU delivered a few reports on 
the safety and environmental assessment of fusion power. The successor study of commercial power plants (European Power Plant Conceptual Study (PPCS) [23]) focussed on five models that spanned a wide range of near-term and advanced physics/technologies. The study highlighted the need to establish the basic features of Demo-a device that bridges the gap between ITER and the first-of-akind fusion power plant.

Figure 2. Timeline and main features of US tokamak power plant studies.

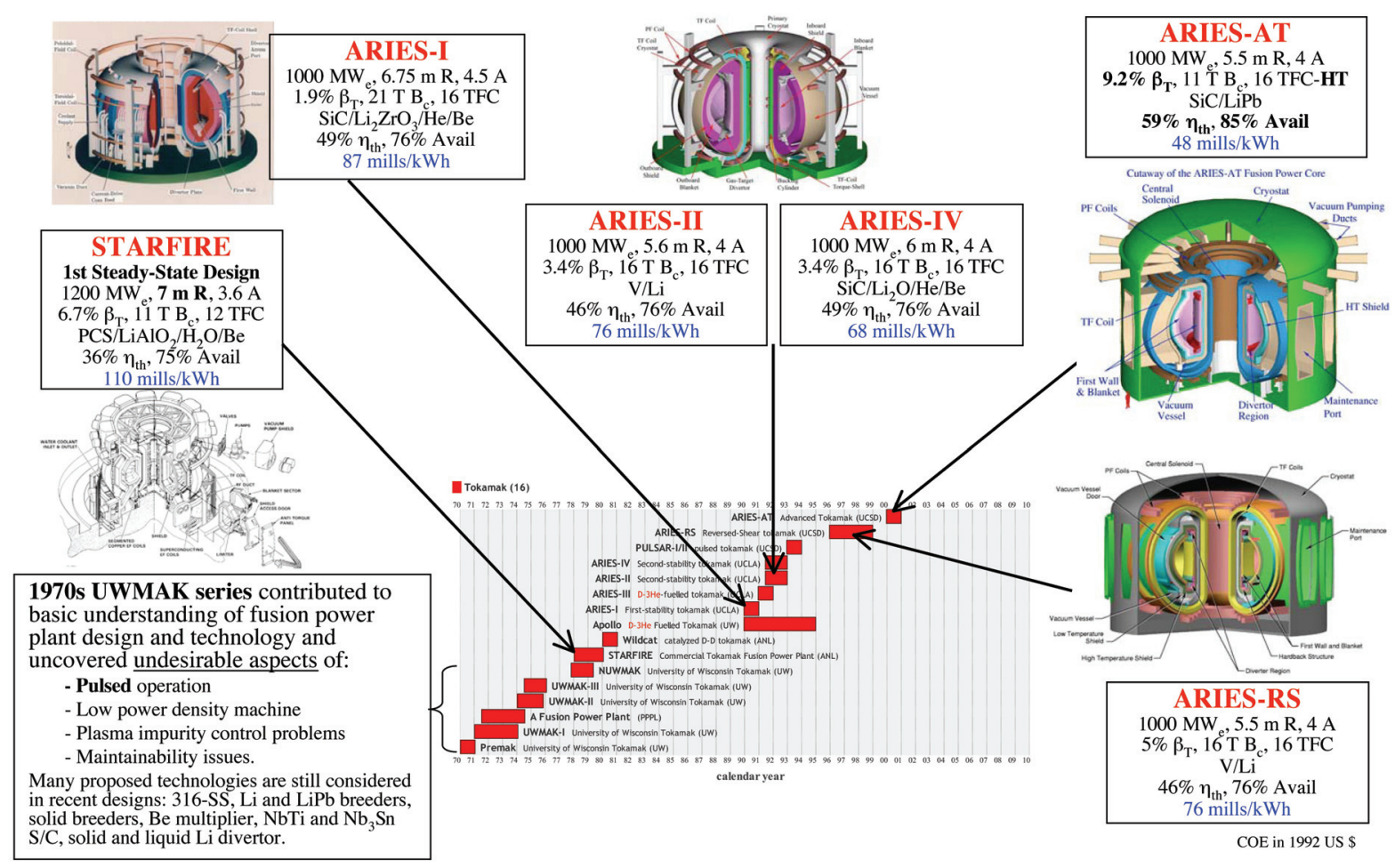

Figure 3. Timeline and main features of non-US tokamak power plant studies.

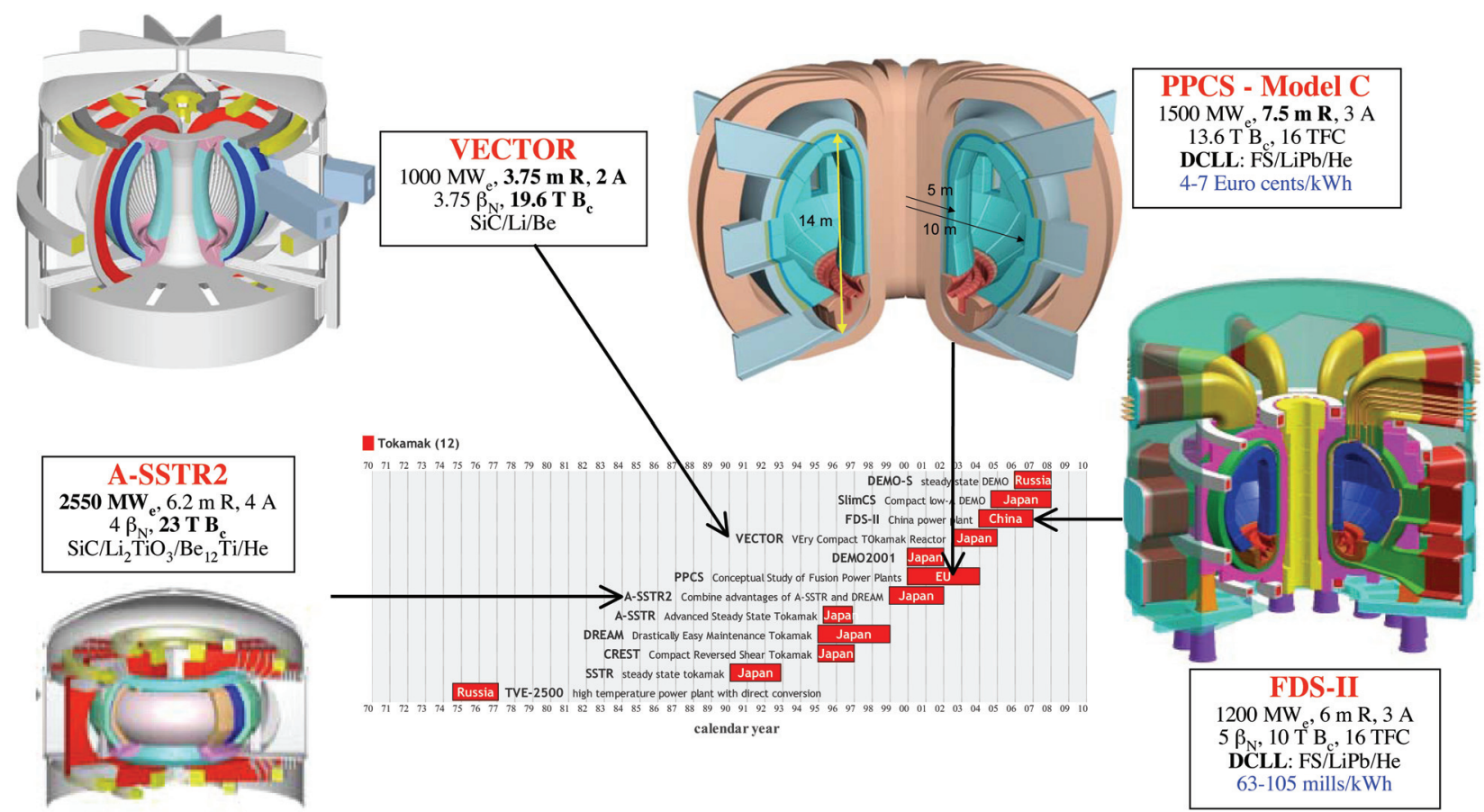


In Japan, a series of pioneer studies (SSTR [24]) was developed in the 1990s to achieve high power density through high field strength at the magnet. The successor DREAM [25] and CREST [26] studies promoted the approach of easier and faster power core maintenance to achieve high overall availability. The most recent VEry Compact TOkamak Reactor (VECTOR) [27], shown in Figure 3, is very compact with a major radius of $3.75 \mathrm{~m}$ and $>16 \mathrm{~T}$ superconducting TF magnets operating at $20 \mathrm{~K}$. VECTOR's design features were incorporated in the design of a compact Demo (SlimCS) with low A and slim central solenoid [28].

Over the past 10 years, China developed a series of fusion design studies (FDS), covering a broad range of tokamak concepts, including a hybrid tokamak to transmute fission products and breed fissile fuels (FDS-I), electricity generator (FDS-II), hydrogen producer (FDS-III), and spherical tokamak (FDS-ST) to examine innovative approaches. Selected parameters of FDS-II [29] are displayed in Figure 3.

Stellarator: In 1950, Spitzer proposed the stellarator concept for controlled fusion. The first device was built in 1951 in the US at Princeton. Later, other experiments have been built in the US, Germany, Japan, Russia, Spain, and Australia. The interest in stellarators stems from their potential physics advantages over tokamaks as inherently steady-state devices with no need for large plasma current, no external current drive, no risk of plasma disruptions, low recirculating power due to the absence of current-drive requirements, and no instability and positional control systems.

Since the early $1980 \mathrm{~s}$, seven large-scale stellarator power plant designs have been developed in Russia, US, Germany, and Japan: RT [30], UWTOR-M [31], ASRA-6C [32], SPPS [33], ARIES-CS [34], HSR [35], and FFHR [36]. These studies vary in scope and depth and encompass a broad range of configurations, as shown in Figure 4.

Figure 4. Timeline and main features of stellarator power plant studies.

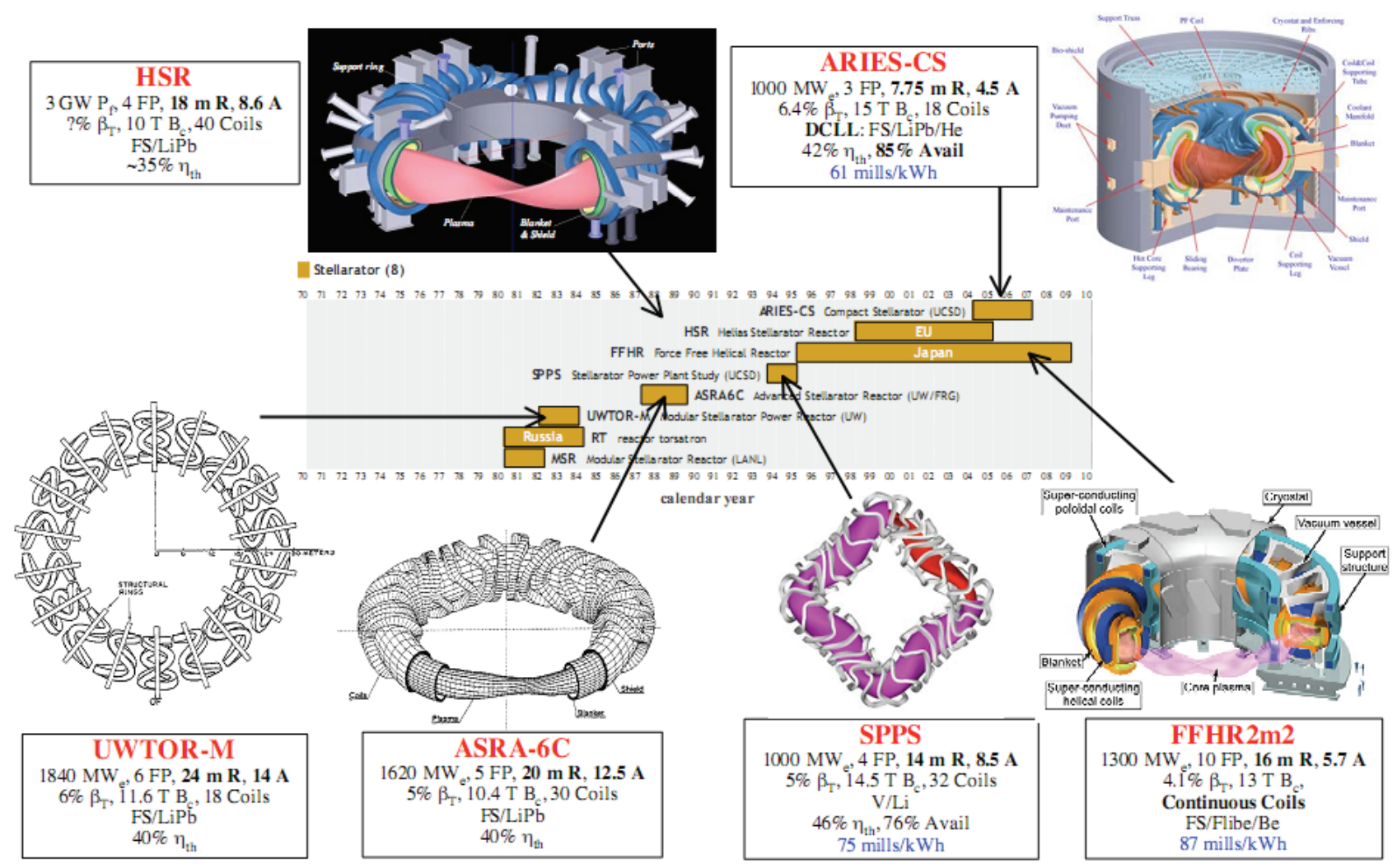


Unlike tokamaks, the stellarator coils are non-planar with highly distorted shapes that repeat in a periodic series. Some of the early designs suggested continuously wound TF coils around the plasma chamber. Later, they were redesigned to be separate, modular coils that repeat in each period. The field periods can be as low as two, but three or more periods are more typical. This results in a plasma shape that is highly distorted and is repeated for each field period. The magnetic field components vary in all three coordinates. In most designs developed to date, the first wall (FW) and surrounding in-vessel components conform to the non-uniform plasma shape to reduce the machine size. The FW shape varies toroidally and poloidally, representing a challenging 3-D engineering problem and making the design of in-vessel components, overall integration process, and maintenance scheme more complex than for tokamaks.

The first large-scale stellarator design in the US (UWTOR-M [31]) was developed by the University of Wisconsin (UW) in the early 1980s. UWTOR-M was followed by the ASRA-6C study [32] that was performed in collaboration between the US and Germany. Next came the Stellarator Power Plant Study (SPPS) [33] initiated in 1995 by the ARIES team to address specific issues for stellarators. A Helias Stellarator Reactor (HSR) study [35] was developed in Germany in the late 1990s based on the W7-X experiment. The stellarator configuration can also be produced using continuous helical coils. An example of this approach is the Japanese Force Free Helical Reactor (FFHR) study [36] based on the LHD experiment.

The 1980s and 1990s stellarator studies led to large power plants mainly due to the relatively large aspect ratio (A) and other design constraints. In the 2000s, the ARIES team launched ARIES-CS [34]-a compact stellarator power plant. Recent advances in physics and technology and innovative radial build design helped reduce the major radius of ARIES-CS by more than 3-fold compared to UWTOR-M, approaching that of advanced tokamaks. Existing worldwide experiments will enhance the physics database further while the overall stellarator program will continue optimizing its design parameters, resolving the challenging divertor issues, and simplifying the relatively complex coil design.

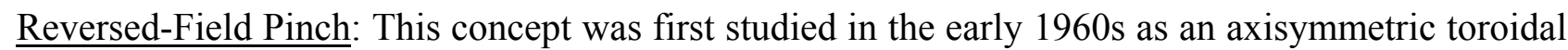
geometry. Since then, the theoretical and experimental bases for RFP have grown remarkably. The configuration is much like a tokamak except for the more than 10-fold weaker toroidal magnetic field. The confining magnetic field is generated primarily by a large driven plasma current. The dominant magnetic field at the plasma edge is poloidal. The weak applied toroidal magnetic field leads to positive attributes: high beta, high mass power density, and normal coils with less shielding. The RFP could operate in a steady-state mode using innovative current drive techniques. A conducting shell surrounding the plasma is normally required to stabilize the current-driven instabilities.

The foremost RFP experiment was built in the US in the mid-1980s [37]. Three other modern facilities (RFX in Italy, RELAX in Japan, and EXTRAP-T2R in Sweden) form the key elements of the international RFP experimental program. In the 1980s, the advantages of RFP as a power plant have been demonstrated through a few conceptual studies [38-40]. The major differences between these designs are in the physics and engineering parameters (refer to Figure 5). The earlier design [38] operated in a pulsed mode with relatively low neutron wall loadings $\left(\sim 5 \mathrm{MW} / \mathrm{m}^{2}\right)$ and employed superconducting magnets. The 1990 TITAN study [40] was based on a set of strong, unproven physics assumptions. In fact, the ongoing US and worldwide RFP experimental program aims to validate the TITAN physics assumptions among others. TITAN delivered two different designs for compact, high 
mass power density power plants. More recently, Miller [41] modified the TITAN characteristics by introducing the modern engineering and economic approaches of ARIES-AT [22].

Figure 5. Timeline and main features of reversed-field pinch power plant studies.

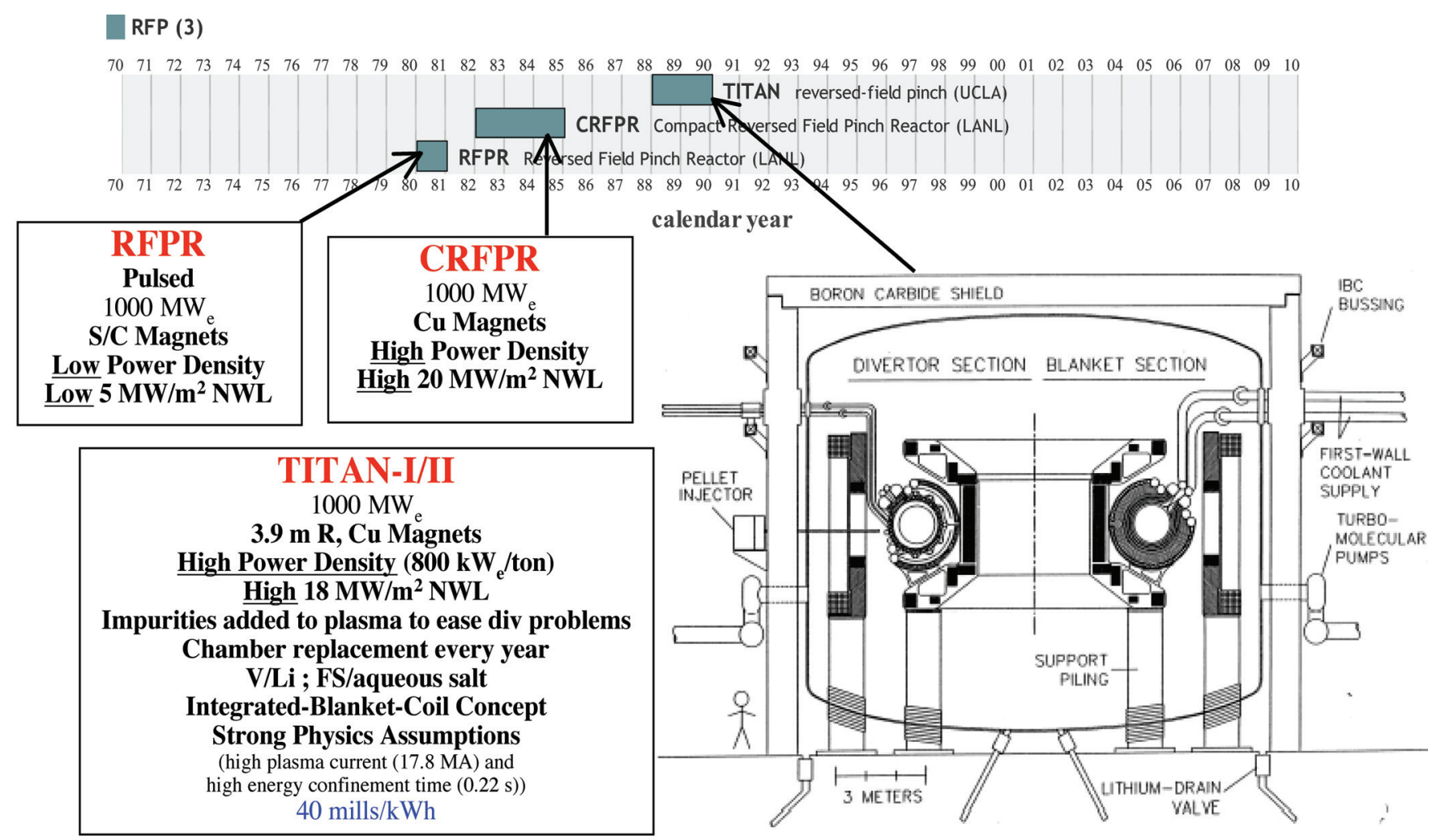

Tandem Mirror: Research embarked on decades of single-cell mirror physics beginning in the 1950s [42]. By the mid 1970s, the TM concept was simultaneously proposed in the US [43] and Russia [44]. Unlike tokamaks, TM is linear in nature, more amenable to maintenance compared to toroidal systems, and offers high beta (30-70\%), no driven plasma current eliminating disruptions, and the potential for direct conversion of charged particle power into electricity at high efficiency. The basic configuration is a long central cell $(\sim 100 \mathrm{~m}$ or more) with $\sim 5 \mathrm{~T}$ solenoidal coils terminated on both sides by end mirror cells and direct conversion systems as shown in Figure 6.

In the 1980s, a few major TM experimental facilities were built in the US (MFTF-B and TMX-U) besides smaller experiments in Russia and Japan (GAMMA 10). Even though MFTF-B was built in the US, it never operated. The 1980 activities delivered four conceptual power plant designs fuelled with D-T and D- ${ }^{3} \mathrm{He}$ : WITAMIR [45], MARS [46], MINIMARS [47], and Ra [48]. Figure 6 displays the basic configuration of the most compact D-T fuelled MINIMARS [47] that was designed to generate $600 \mathrm{MW}_{\mathrm{e}}$ of net electric power using $139 \mathrm{~m}$ long central cell and gridless direct conversion system.

Even though the TM concept was a strong contender on the 1980s, it seems that it has no strong growth potential in the future. In 1986, the US Department of Energy canceled the nearly completed MFTF-B TM experiment and terminated the US TM program in favor of the more promising tokamak and five other alternate concepts. Internationally, the GAMMA 10 TM experiment at the University of Tsukuba, Japan is regarded as an educational device, rather than a facility for energy research. The 
development of magnetic traps is progressing in Russia at the Budker Institute of Nuclear Physics where two facilities are under operation: the gas-dynamic trap and multi-plug trap; neither of these is a TM.

Figure 6. Timeline and main features of tandem mirror power plant studies.

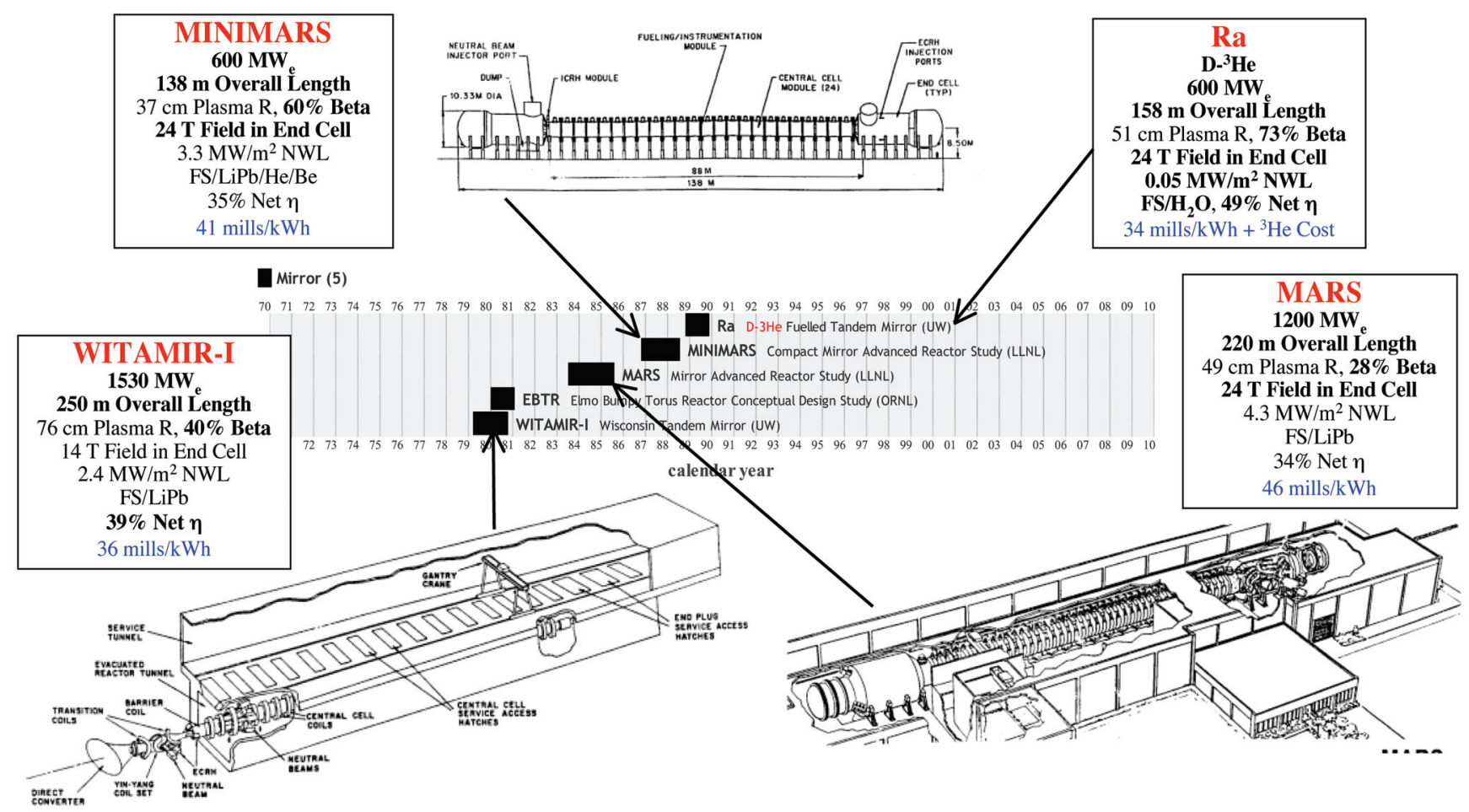

\subsection{New Concepts: Spherical Torus, Field-Reversed Configuration, and Spheromak}

Spherical Torus: In the 1980s, Peng et al. [49] identified unique physics features of ST as a low aspect ratio machine with good plasma confinement, high toroidal beta (that enhances the fusion power), high bootstrap current (that reduces the external current drive), and resiliency to major disruptions. Geometrically, the ST shape is quite different from the donut D-shape plasma for tokamaks. ST is tall with elongated plasma and a central hole to accommodate the inner legs of the TF coil and their shield (as there is no inner blanket). The toroidal field is 2-3-fold less powerful in STs compared to tokamaks, allowing the use of normal, non-superconducting magnets. However, the resistive losses in these magnets would be significant, requiring large recirculating power and higher fusion power.

At present, there are 20 ST experiments in the world [50]. NSTX in the US and MAST at UK are the largest operational facilities. The experimental achievements of the 1990s promoted interest in exploring the ST potential as a power plant. As such, two power plant studies in the US and UK have been made of the ST concept with A = 1.4-1.6: ARIES-ST [51] and UK-ST [52] (see Figure 7). The most challenging engineering issues are designing both divertor (to handle the very high heat flux $\left(>20 \mathrm{MW} / \mathrm{m}^{2}\right.$ ) and center post (to reduce the Joule losses and shielding requirements, and to be an easily replaceable component every few years), and developing a low cost fabrication approach to allow an economic replacement of the sizable center leg. 
Figure 7. Timeline and main features of spherical torus power plant studies.

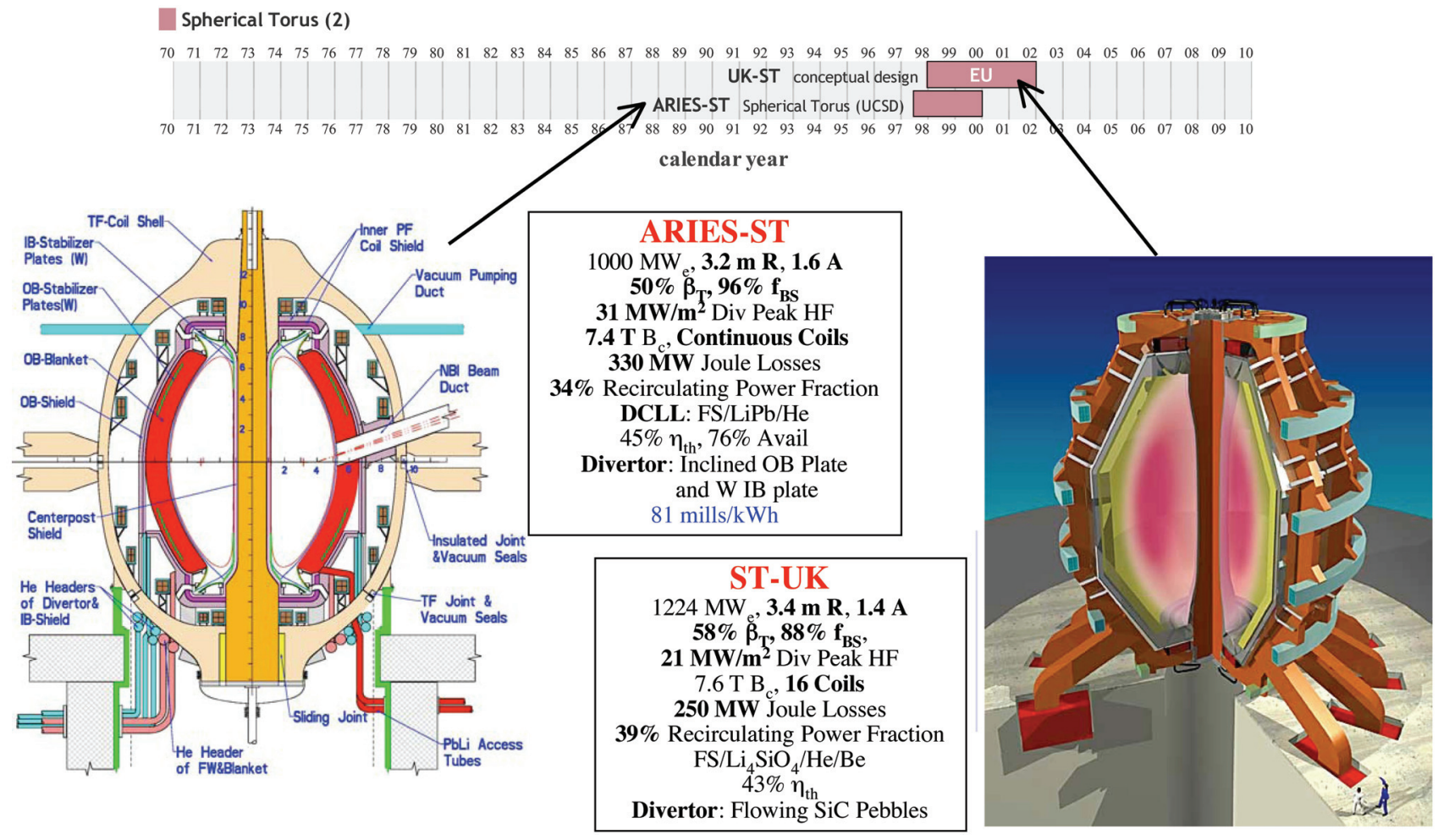

Field-Reversed Configuration: The FRC belongs to a set of compact tori that also includes the spheromak, representing one of the simplest configurations that can be envisioned for a fusion device. Geometrically, it is a linear, open-ended cylindrical system, consisting of nested magnetic flux surfaces (created by currents flowing inside the plasma) embedded inside a linear magnetic field (created by external magnets). Key features include low magnetic fields and very high beta (50-100\%). The cylindrical chamber is relatively simple and permits easy construction and maintenance of all components. The world's largest experimental facility (TCSU/LSX) exists in the US at the University of Washington. Twelve other smaller-scale FRC facilities are operational around the world.

Beginning in the 1970s, researchers examined the potential of the FRC concept as an energy-producing power plant in a pulsed mode of operation. As Figure 8 indicates, the 1990s witnessed the emergence of D-T and $\mathrm{D}-{ }^{3} \mathrm{He}$ fuelled FRC designs with a steady-state operation that solved many of the pulsed system problems. One of the challenging FRC physics issues is sustaining the plasma current during the steady-state operation. Several researchers proposed the use of rotating magnetic field (RMF) current drive to sustain the FRC configuration [53,54]. Later, interest in compactness surfaced to reduce the FRC cost of electricity. As a result, the neutron wall loading exceeded the design limit $\left(\sim 5 \mathrm{MW} / \mathrm{m}^{2}\right)$ and called for advanced fuels with fewer neutrons (such as the D- ${ }^{3}$ He fuelled RUBY [55], ARTEMIS [56], and RF/UW FRC [57]) or an innovative FW protection scheme, such as liquid walls [58]. Indeed, the D- ${ }^{3} \mathrm{He}$ fuelled designs (with $25-35 \mathrm{~m}$ long chamber and $<1 \mathrm{MW} / \mathrm{m}^{2} \mathrm{NWL}$ ) and the liquid wall design (with $10 \mathrm{~m}$ long chamber and $18 \mathrm{MW} / \mathrm{m}^{2} \mathrm{NWL}$ ) demonstrated less severe FW problems. However, a few remaining issues still hinder the progress of the FRC concept: plasma stability, energy confinement, and an efficient method for current drive.

Figure 8. Timeline and main features of field-reversed configuration power plant studies. 


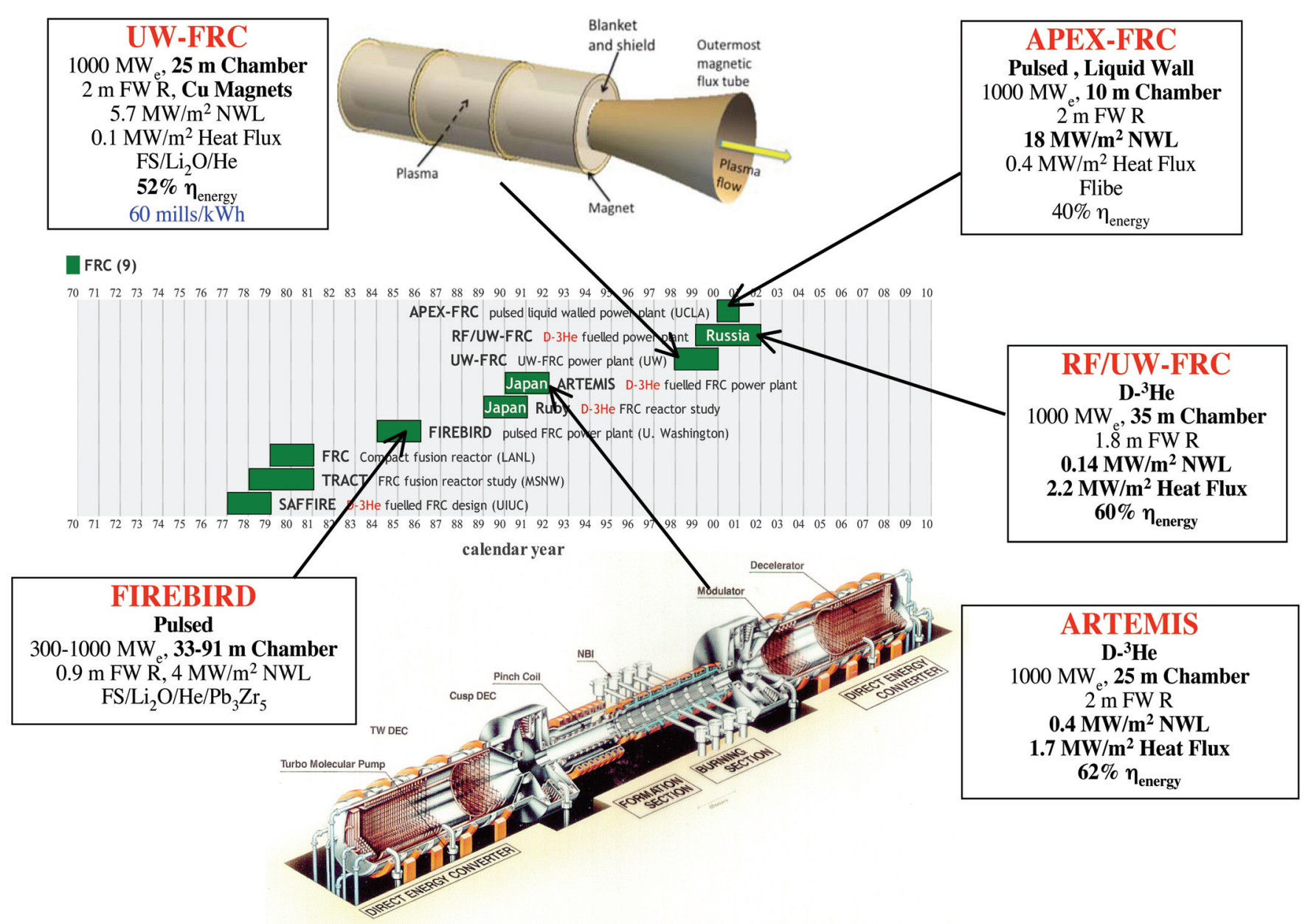

Spheromak: It offers a truly compact fusion device with low aspect ratio, moderate beta (10-20\%), and comparable toroidal and poloidal fields. It is a toroidally symmetric configuration distinguished from tokamaks and STs by a simple geometry with no toroidal field coils and with no inboard materials. It confines the roughly spherical plasma in a cylindrical chamber using only a small set of external stabilizing coils. The confining magnetic fields are self-generated by the plasma. The superhot, fast-moving plasma produces magnetic fields that pass through the plasma itself, generating more current that reinforces the magnetic fields further.

Over the years beginning in the early 1980s, scientists believed that the simplicity, compactness, and absence of toroidal field coils make the constructability of spheromaks relatively easy and inexpensive compared to tokamaks. Even though the geometry is simple, the plasma behavior is very complex and difficult to predict or control as it often involves magnetic fluctuations and turbulence. Several spheromak experiments have been constructed to understand the plasma behavior. The first US design [59] was launched in the mid-1980s to explore the potential of a steady-state spheromak power plant. The most recent design was developed in the mid-1990s [60] with larger chamber, double X-points, high NWL, and high surface heat flux at the divertor, suggesting the consideration of a liquid wall to protect the structure against radiation. Figure 9 displays the main features of both designs. 
Figure 9. Timeline and main features of spheromak power plant studies.

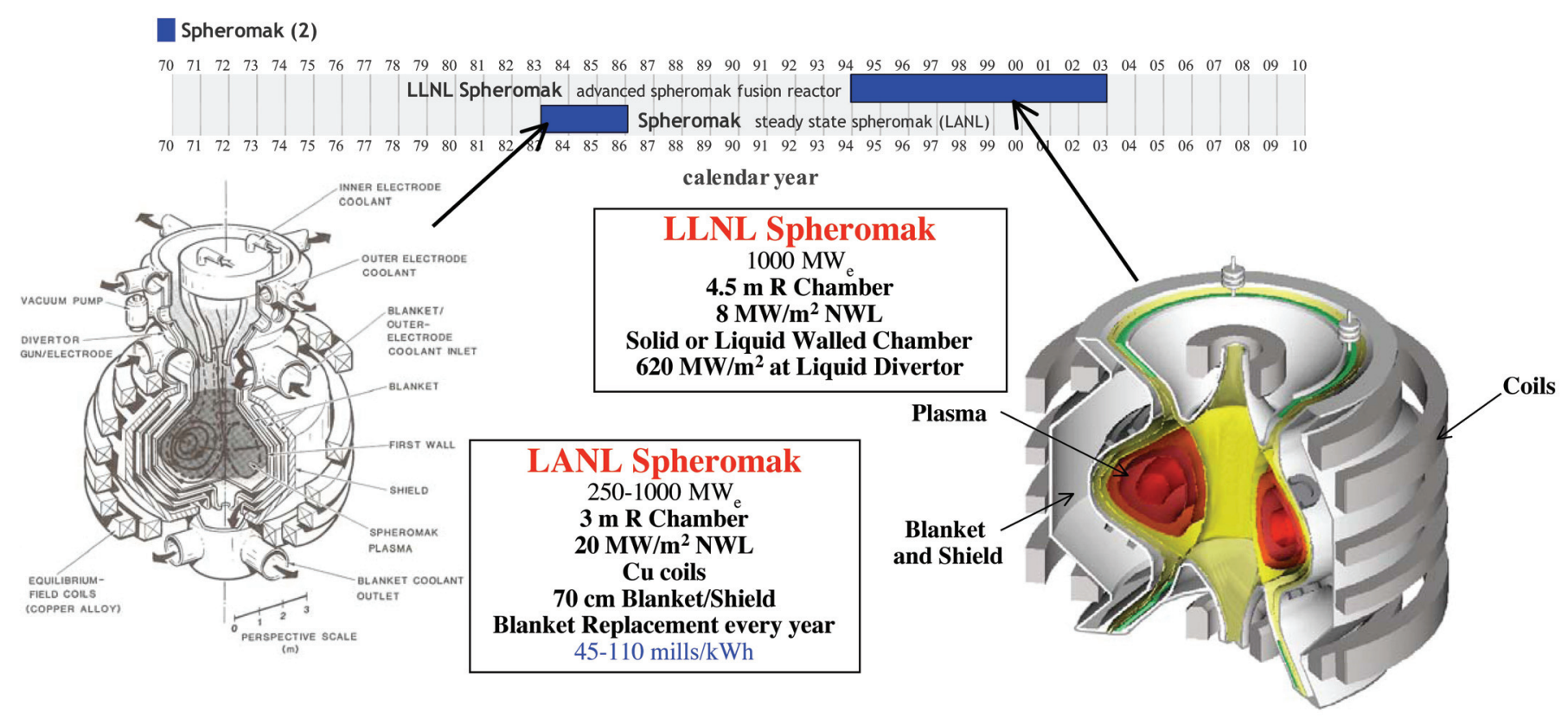

\section{Discussion of Future Trends}

Since the beginning of fusion development in the early 1970s, researchers have been developing long-term plans and schedules with the end goal of operating fusion power plants in 50 years (i.e., by 2020). This has been a sliding scale vision. Today, it is still uncertain when exactly fusion will contribute to the commercial energy mix, perhaps in several decades, extending the timetable far beyond the famous 50 years of the 1970s, or probably in a few decades if the social and political climate creates a demand for fusion energy maintained with unlimited funding and strong governmental support.

Among the seven magnetic concepts developed to date, the D-T fuelled tokamak is regarded as the most viable candidate for magnetic fusion energy generation. The R\&D activities for the other six alternate concepts are at lesser levels of maturity. Even if these alternate approaches are not successful in realizing the path to fusion energy, their physics and technology database contributions could offer possible improvements for the tokamak concept in particular and for the broader scientific aspect of the fusion program in general. During the ITER era, existing alternate concept facilities could revise their mission to support and improve the tokamak concept through addressing the important critical issues that face the tokamak, such as high heat loads on divertor and FW, plasma-material interaction issues, plasma instabilities and disruption, etc. In the long term, when fusion plays an important role in the commercial energy market, the non-tokamak concepts may become more efficient and contribute to the energy market.

The main progress in fusion research so far has been directly connected to physics-oriented experimental facilities built in many countries with varying missions and scopes. No country has yet offered a firm commitment to build the next step machine after ITER. Worldwide, the Demo is viewed as the last step necessary to reduce the technical and programmatic risk associated with the first commercial fusion power plant. Beyond ITER, multiple facilities and a strong R\&D program are needed to bridge the large gap between existing experiments and Demo operation. Significant fusion 
technologies and several new facilities still remain to be developed and constructed before designing and building the Demo, which will cost billions of dollars.

Although existing experiments and ITER will demonstrate the basic physics and technologies needed for fusion operation (such as plasma confinement and control, shielding system, and superconducting magnet performance), other classes of technology and engineering options have yet to be demonstrated before building a credible Demo. These include high performance divertors, high-temperature tritium breeding blankets, radiation resistant materials, diagnostic systems, and resilient components with high levels of reliability and maintainability [61]. Besides an extensive R\&D program to address these technological issues, validation of all subsystems with long term testing in a relevant high flux neutron environment is essential to minimize the risk of building and operating Demo as the fusion power plant of the future.

The pressing questions are: How are the various design options selected and validated for incorporation and integration into the Demo? What are the necessary steps to move the preferred option to a higher level of confidence on the performance toward the end goal of a fusion power plant? The Technology Readiness Level methodology [62] could provide guidance in this regard as it provides an objective measure of the maturity of a particular technology, evaluates the remaining $R \& D$ needs toward the goal of practical fusion energy, and helps identify necessary plans and facilities (i.e. "next step" machines) to sufficiently mature the technology and bridge the gap between ITER and an attractive power plant.

Advanced fuel cycles (other than D-T) could be the ultimate response to the safety and environmental requirements for fusion power plants. These advanced fuel cycles (with much fewer neutrons than D-T) offer clear technological advantages in addition to the attractive safety/environmental characteristics. For instance, existing technology would enable the design and construction of advanced-fuelled devices with no need for a tritium breeding blanket, all permanent components, and possibly direct energy conversion of charged particles into electricity with $60 \%$ conversion efficiency [63]. However, the advanced fuel cycles have their own set of physics issues and concerns-mainly the attainment of much higher plasma parameters that are required to achieve fusion conditions. Past efforts in the 1970s and 1980s focused on non-tokamak concepts (FRC and TM) with high beta and high magnetic field. Because of the very challenging physics of the advanced fuel cycles, almost all existing operational experiments and fusion studies will continue employing the D-T fuel cycle with the least demanding physics conditions to reach ignition.

At present, the schedule for placing a fusion power plant on the grid is uncertain despite the numerous long-range plans [64-68] developed to date. Besides the lack of funding and necessary political support, the prime reasons are the unreadiness of almost all necessary technologies, the varying degree of physics extrapolation from ITER to advanced power plants, and the lack of a demonstrated, fully-integrated fusion facility. Fusion advocates in their power plant designs and developmental plans manifested these factors in quite varied philosophies. Consequently, the worldwide pathways for fusion energy proposed over the past decade take different approaches, depending on the degree of assumed technology readiness, the extent of physics and technology extrapolation beyond ITER, and the desired economic competitiveness of the power plant design. Some countries believe that ITER will provide all the necessary R\&D sufficient to design and build 
their own Demo while other countries feel that there are many technical stepping-stones that remain to be validated before building a Demo, including building and operating a Component Test Facility.

Several countries projected operating tokamak Demo plants in 25-30 years from now, including Korea, US, Japan, EU, China, Russia, and India, covering a wide range of near-term and advanced tokamak systems. Figure 10 displays a collection of unofficial projections for the tokamak concept of when the Demo and first commercial fusion power plant might be built separately by various nations [69]. The most optimistic projection is by the Koreans with a scenario for the first fusion power plant adding electricity to the grid in the 2040s [68]. The other countries are targeting fusion power production in the 2050s. If the energy market favors accelerating the development of fusion with a substantial increase in funding and governmental support, it is felt that commercial production of fusion energy could be achieved as early as 2030 [69].

Figure 10. Projection of Demo and first power plant operation.

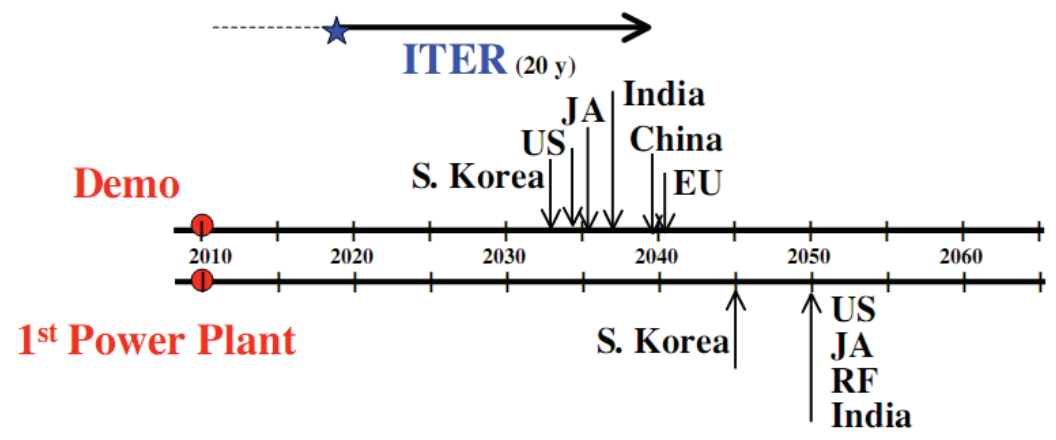

\section{References and Notes}

1. Fifty years of magnetic confinement fusion research-retrospective. International Atomic Energy Agency: Vienna, Austria, 2008. Available online: http://www-naweb.iaea.org/napc/physics/ 2ndgenconf/sets/Home.html (Accessed on 30 April 2010).

2. El-Guebaly, L.A. History and evolution of fusion power plant studies: Past, present, and future prospects. In Nuclear Reactors, Nuclear Fusion and Fusion Engineering; Aasen, A., Olsson, P., Eds; NOVA Science Publishers, Inc: Hauppauge, NY, USA, 2009; pp. 217-271.

3. El-Guebaly, L.A. Basic concepts of thermonuclear fusion. In Wiley Encyclopedia of Energy Science, Technology \& Application; Wiley Publishers: Hoboken, NJ, USA, to be published.

4. INTOR Group. International tokamak reactor: Phase two A, Part III: Report of International Workshop, 1985-1987, IAEA, Vienna, Austria, 1988.

5. Stacey, W.M. The Quest for a Fusion Energy Reactor: An Insider's Account of the INTOR Workshop; Oxford University Press: Cary, NC, USA, 2010.

6. The ITER Project. Available online: http://www.iter.org/ (Accessed on 30 April 2010).

7. Sheffield, J. The physics of magnetic fusion reactors. Rev. Mod. Phys. 1994, 66, 1015-1103.

8. Lyon, J.F.; Gulec, K.; Miller, R.L.; El-Guebaly, L. Status of the U.S. stellarator reactor study. Fusion Eng. Des. 1994, 25, 85-103.

9. Morley, N.B.; Abdou, M.A.; Anderson, M.; Calderoni, P.; Kurtz, R.J.; Nygren, R.; Raffray, R.; Sawan, M.; Sharpe, P.; Smolentsev, S.; et al. Overview of fusion nuclear technology in the US. Fusion Eng. Des. 2006, 81, 33-43. 
10. Andreani, R.; Diegele, E.; Gulden, W.; Lässer, R.; Maisonnier, D.; Murdoch, D.; Pick, M.; Poitevin, Y. Overview of European Union fusion nuclear technologies development and essential elements on the way to demo. Fusion Eng. Des. 2006, 81, 25-32.

11. Tanaka, S. Overview of research and development activities on fusion nuclear technologies in Japan. Fusion Eng. Des. 2006, 81, 13-24.

12. Strebkov, Y.; Belyakov, V. Review of the activity in Russia in the area of fusion nuclear technology. Fusion Eng. Des. 2006, 81, 45-58.

13. Wu, Y. Conceptual design activities of FDS series fusion power plants in China. Fusion Eng. Des. 2006, 81, 2713-2718.

14. Worldwide Tokamak Experiments. Available online: http://www.toodlepip.com/tokamak/ conventional-large-tokamaks.htm (Accessed on 30 April 2010).

15. Badger, B.; Audenaerde, K.; Avci, H.; Beyer, J.; Blackfield, D.; Boom, R.W.; Cameron, E.; Cheng, E.; Conn, R.W.; Emmert, G.A.; et al. NUWMAK-A tokamak reactor design study. University of Wisconsin Fusion Technology Institute Report, Madison, WI, USA, 1979; UWFDM-330. Available online: http://fti.neep.wisc.edu/pdf/fdm330.pdf. (Accessed on 30 April 2010).

16. Vasil'ev, N.N.; Lukash, V.E.; Nedospasov, A.V.; Nefedkina, L.B.; Petrov, V.G.; Tokor, M.Z.; Kolbasov, B.N.; Kurbatov, D.K.; Orlov, V.V.; Pistunovich, V.I.; Shatalov. G.E. Concept of tokamak-type reactor with high temperature blanket. In Proceedings of the $7^{\text {th }}$ International Conference on Plasma Physics and Controlled Nuclear Fusion Research, Innsbruck, Austria, 23-30 August 1978; IAEA, Vienna, Austria, 1979, Volume III, pp. 379-386.

17. Baker, C.C.; Abdou, M.A.; Arons, R.M.; Finn, P.A.; Misra, B.; Bolon, A.E.; Fuja, R.E.; Rest, J.; Boley, C.D.; Gohar, Y.; et al. STARFIRE-A commercial tokamak fusion power plant study. Argonne National Laboratory Report, Argonne, IL, USA, 1980, ANL/FPP-80-1.

18. The ARIES project. Available online: http://aries.ucsd.edu/ARIES/ (Accessed on 30 April 2010).

19. Najmabadi, F.; Conn, R.W.; Cooke, P.I.; Grotz, S.P.; Hasan, M.Z.; Ibrahim, E.; Kunugi, T.; Mau, T.K.; Martin, R.C.; Sharafat, S.; et al. The ARIES-I tokamak fusion reactor study-the final report. University of California Los Angeles Report, Los Angeles, CA, USA, 1991, UCLA-PPG-1323.

20. Najmabadi, F.; Conn, R.W.; Bathke, C.G.; Baxi, C.B.; Bromberg, L.; Brooks, J.; Cheng, E.T.; Davis, F.; Ehst, D.A.; El-Guebaly, L.A.; et al. ARIES-II and ARIES-IV second-stability tokamak reactors. Fusion Technol. 1992, 21, 1721-1728.

21. Najmabadi, F.; Bathke, C.G.; Billone, M.C.; Blanchard, J.P.; Bromberg, L.; Chin, E.; Cole, F.R.; Crowell, J.A.; Ehst, D.A.; El-Guebaly, L.A.; et al. Overview of ARIES-RS reversed shear power plant study. Fusion Eng. Des. 1997, 38, 3-25.

22. Najmabadi, F.; Abdou, A.; Bromberg, L.; Brown, T.; Chan, V.C.; Chu, M.C.; Dahlgren, F.; El-Guebaly, L.; Heitzenroeder, P.; Henderson, D.; et al. The ARIES-AT advanced tokamak, advanced technology fusion power plant. Fusion Eng. Des. 2006, 80, 3-23.

23. Maisonnier, D.; Cook, I.; Sardain, P.; Andreani, R.; Di Pace, L.; Forrest, R.; Forrest, R.; Giancarli, L.; Hermsmeyer, S.; Norajitra P.; et al. A conceptual study of fusion power plants. European Fusion Development Agreement Final Report, 2005, EFDA-RP-RE-5.0. Available online: http://www.efda.org/eu_fusion_programme/scientific_and_technical_publications.htm (Accessed on 30 April 2010). 
24. Nishio, S.; Tobita, K.; Ushigusa, K.; Konishi, S. Conceptual design of tokamak high power reactor (A-SSTR2). Plasma Fusion Res. 2002, 78, 1218-1230.

25. Nishio, S.; Murakami, Y.; Adachi, J.; Miura, H.; Aoki, I.; Seki, Y. The concept of drastically easy maintenance (DREAM) tokamak reactor. Fusion Eng. Des. 1994, 25, 289-298.

26. Okano, K.; Asaoka, Y.; Hiwatari, R.; Inoue, N.; Murakami, Y.; Ogawa, Y. Tokimatsu, K.; Tomabechi, K.; Yamamoto, T.; Yoshida T. Study of a compact reversed shear tokamak reactor. Fusion Eng. Des. 1998, 41, 511-517.

27. Nishio, S.; Tobita, K.; Konishi, S.; Ando, T.; Hiroki, S.; Kuroda, T.; Yamauchi, M.; Azumi, M.; Nagata, M. Tight aspect ratio tokamak power reactor with superconducting TF coils. In Proceedings of $19^{\text {th }}$ IAEA Fusion Energy Conference, Lyon, France, 2002, FT/P/1-21. Available online: http://www-pub.iaea.org/MTCD/publications/PDF/csp_019c/html/node362.htm\#74213 (Accessed on 30 April 2010).

28. Tobita, K.; Nishio, S.; Sato, M.; Sakurai, S.; Hayashi, T.; Shibama, Y.K.; Isono, T.; Enoeda, M.; Nakamura, H.; Sato, S.; et al. SlimCS-compact low aspect ratio demo reactor with reduced-size central solenoid. Nucl. Fusion 2007, 47, 892-899.

29. Wu, Y. Conceptual design of the china fusion power plant FDS-II. Fusion Eng. Des. 2008, 83, 1683-1689.

30. Emel'yanov, G.S.; Kantan, V.V.; Semyonov, A.A.; Bykov V.E.; Volkov E.D.; Georgievskij A.V.; Rudakov V.A.; Sergeev Yu.F.; Suprunenko V.A.; Yuferov V.B.; et al. Thermonuclear electrical power plant with reactor-torsatron (in Russian), In Proceedings of $2^{\text {nd }}$ All-Union Conference on Engineering Problems of Fusion Reactors, Leningrad, Russia, NIIEFA, 23-25 June, 1981; Volume 1, p. 143.

31. Badger, B.; Sviatoslavsky, I.N.; Van Sciver, S.W.; Kulcinski, G.L.; Emmert, G.A.; Anderson, D.T.; Bailey, A.W.; Callen, J.D.; Derr, J.A.; El-Guebaly, L.; et al. UWTOR-M, a conceptual modular stellarator power reactor. University of Wisconsin Fusion Technology Institute Report, Madison, WI, USA, 1982, UWFDM-550. Available online: http://fti.neep.wisc.edu/pdf/fdm550.pdf (Accessed on 30 April 2010).

32. Böhme, G.; El-Guebaly, L.A.; Emmert, G.A.; Grieger, G.; Harmeyer, E.; Herrnegger, F.; Huebener, J.; Jentzsch, K.; Kisslinger, J.; Komarek, P.; et al. Studies of a modular advanced stellarator reactor ASRA6C. Fusion Power Associates Report, Madison, WI, USA, 1987, FPA-87-2. Available online: http://fti.neep.wisc.edu/pdf/fpa87-2.pdf (Accessed on 30 April 2010).

33. Miller, R.; The SPPS team. The stellarator power plant study. University of California San Diego Report, San Diego, CA, USA, 1997, UCSD-ENG-004.

34. Najmabadi, F.; Raffray, A.R.; The ARIES-CS team. The ARIES-CS compact stellarator fusion power plant. Fusion Sci. Technol. 2008, 54, 655-672.

35. Igitkhanov, Y.; Andreeva, T.; Beidler, C.D.; Harmeyer, E.; Herrnegger, F.; Kisslinger, J.; Wagner, F.; Wobig, H. Status of HELIAS reactor studies. Fusion Eng. Des. 2006, 81, 2695-2702.

36. Sagara, A.; Mitarai, O.; Tanaka, T.; Imagawa, S.; Kozaki, Y.; Kobayashi, M.; Morisaki, T.; Watanabe, T.; Takahata, K.; Tamura, H.; et al. Optimization activities on design studies of LHD-type reactor FFHR. Fusion Eng. Des. 2008, 83, 1690-1695.

37. The MST Experiment. Available online: http://plasma.physics.wisc.edu/mst $/ \mathrm{html} / \mathrm{mst} . \mathrm{htm}$ (Accessed on 30 April 2010). 
38. Hancox, R.; Krakowski, R.A.; Spears, W.R. The reversed field pinch reactor. Nucl. Eng. Des. 1981, 63, 251-270.

39. Krakowski, R.A.; Hagenson, R.L.; Schnurr, N.M.; Copenhaver, C.; Bathke, C.G.; Miller, R.L.; Embrechts, M.J. Compact reversed-field pinch reactors (CRFPR). Nucl. Eng. Des. Fusion 1986, $4,75-120$.

40. Najmabadi, F.; Ghoniem, N.; Conn, R.W.; Blanchard, J.; Chu, Y.; Cooke, P.I.; Grotz, S.P.; Hasan, M.Z.; Kessel, C.E.; Martin, R.C.; et al. The TITAN Reversed-Field-Pinch Fusion Reactor Study-the Final Report; UCLA-PPG-1200; University of California, Los Angeles: Los Angeles, CA, USA, 1990.

41. Miller, R.L. Power plant considerations for the reversed-field pinch (RFP). Fusion Sci. Technol. 2009, 56, 940-944.

42. Fowler, T.K. Fusion research in open-ended systems. Nucl. Fusion 1969, 9, 3.

43. Fowler, T.K.; Logan, B.G. The tandem mirror reactor. Comment. Plasma Phys. Contr. Fusion 1977, 2, 167.

44. Dimov, G.I.; Zakaidakov, V.V.; Kishinevsky, M.E. Thermonuclear confinement with twin mirror system. Sov. J. Plasma Phys. 1976, 2, 326.

45. Badger, B.; Audenaerde, K.; Beyer, J.B.; Braun, D.; Callen, J.D.; Emmert, G.A.; Gilmore, J.M.; Hoffman, N.; Kesner, J.; Kulcinski, G.L.; et al. WITAMIR-I, a university of wisconsin tandem mirror reactor design. University of Wisconsin Fusion Technology Institute Report, Madison, WI, USA, 1980, UWFDM-400. Available online: http://fti.neep.wisc.edu/pdf/fdm400.pdf (Accessed on 30 April 2010).

46. Logan, B.G.; Henning, C.D.; Carlson, G.A.; Werner, R.W.; Baldwin, D.E.; Dorn, D.W.; Kumai, W.N.; Barr, W.L.; Hamilton, G.W.; Maninger, R.C.; et al. Mirror Advanced Reactor Study (MARS) Final Report; UCRL-53480; Lawrence Livermore National Laboratory: Livermore, CA, USA, 1984.

47. Lee, J.D.; Barr, W.L.; Bulmer, R.H.; Devoto, R.S.; Doggett, J.N.; Fink, J.H.; Johnston, B.M.; Logan, B.G.; Maninger, R.C.; Moir, R.W.; et al. MINIMARS Conceptual Design: Final Report; UCID-20773; Lawrence Livermore National Laboratory: Livermore, CA, USA, 1986.

48. Santarius, J.F.; Attaya, H.M.; Corradini, M.L.; El-Guebaly, L.A.; Emmert, G.A.; Kulcinski, G.L.; Larsen, E.M.; Maynard, C.W.; Musicki, Z.; Sawan, M.E.; et al. Ra: A high efficiency, D- ${ }^{3} \mathrm{He}$, tandem mirror fusion reactor. In Proceedings of $12^{\text {th }}$ IEEE Symposium on Fusion Engineering, Monterey, CA, USA, 12-16 October, 1987; pp. 752-755. Available online: http://fti.neep.wisc. edu/pdf/fdm741.pdf (Accessed on 30 April 2010).

49. Peng, Y.K.M.; Strickler, D.J. Features of spherical torus plasma. Nucl. Fusion 1986, 26, 576.

50. Spherical Tokamaks. Worldwide ST Experiments. Available online: http://www.toodlepip.com/ tokamak/spherical-tokamaks.htm (Accessed on 30 April 2010)

51. Najmabadi, F.; the ARIES Team. Spherical torus concept as power plants-the ARIES-ST study. Fusion Eng. Des. 2003, 65, 143-164.

52. Voss, G.M.; Bond, A.; Hicks, J.B.; Wilson, H.R. Development of the ST power plant. Fusion Eng. Des. 2002, 63, 65-71. 
53. Hoffman, A.L. Flux buildup in field reversed configurations using rotating magnetic fields. Phys. Plasmas 1998, 5, 979.

54. Santarius, J.F.; Mogahed, E.A.; Emmert, G.A.; Khater, H.K.; Nguyen, C.N.; Ryzhkov, S.V.; Stubna, M.D.; Steinhauer, L.C.; Miley, G.H. Final Report for the Field-Reversed Configuration Power Plant Critical-Issue Scoping Study; UWFDM-1129; Fusion Technology Institute, University of Wisconsin, Madison, WI, USA, 2000. Available online: http://fti.neep.wisc.edu/ pdf/fdm1129.pdf. (Accessed on 30 April 2010)

55. Kernbichler, W.; Heindler, H.; Momota, H.; Tomita, Y.; Ishida, A.; Ohi, S.; Sato K.; Miley G.H.; Berk H.L.; Dove W.; et al. D- ${ }^{3} \mathrm{He}$ in field reversed configurations-Ruby: An international reactor study. In Proceedings of $13^{\text {th }}$ International Conference on Plasma Physics and Controlled Nuclear Fusion Research, Washington, DC, USA, 1-6 October, 1990; IAEA: Vienna, Austria, 1991; Volume 3, p. 555.

56. Momota, H.; Ishida, A.; Kohzaki, Y.; Miley, G.H.; Ohi, S.; Ohnishi, M.; Sato, K.; Steinhauer, L.C.; Tomita, Y.; Tuszewski, M. Conceptual design of the D- ${ }^{3} \mathrm{He}$ reactor ARTEMIS. Fusion Technol. 1992, 21, 2307.

57. Khvesyuk, V.I.; Ryzhkov, S.; Santarius, J.F.; Emmert, G.A.; Nguyen, C.N.; Steinhauer, L.C. D- ${ }^{3}$ He field reversed configuration fusion power plant. Fusion Technol. 2001, 39, 410-413.

58. Moir, R.W.; Bulmer, R.H., Gulec, K.; Fogarty, P.; Nelson, B.; Ohnishi, M.; Rensink, M.; Rognlien, T.D.; Santarius, J.F.; Sze, D.K. Thick liquid-walled, field-reversed configuration magnetic fusion power plant. Fusion Technol. 2001, 39, 758-767.

59. Hagenson, R.L.; Krakowski, R.A. Steady-state spheromak reactor studies. Fusion Technol. 1985, $8,1606-1612$.

60. Hooper, E.B.; Fowler, T.K. Spheromak reactor: Physics opportunities and issues. Fusion Technol. 1996, 30, 1390-1394.

61. Waganer, L.M. Fusion technology. In Wiley Encyclopedia of Energy Science, Technology \& Application; Wiley Publishers: Hoboken, NJ, USA, to be published.

62. Tillack, M.S.; Turnbull, A.D.; Waganer, L.M.; Malang, S.; Steiner, D.; Sharpe, J.P.; Cadwallader, L.C.; El-Guebaly, L.; Raffray, A.R.; Najmabadi, F.; Peipert, R.J., Jr.; Weaver, T.L.; The ARIES team. An evaluation of fusion energy R\&D gaps using Technology Readiness Levels. Fusion Sci. Technol. 2009, 56, 949-956.

63. Kulcinski G.L.; Santarius, J.F. New opportunities for fusion in the $21^{\text {st }}$ century-advanced fuels. Fusion Technol. 2001, 39, 480-485.

64. Dean, S.O.; Baker, C.C.; Cohn, D.R.; Kinkead, S.D. An accelerated fusion power development plan. J. Fusion Energ. 1991, 10, 197-206.

65. Goldston R.; Abdou M.; Baker C.; Campbell M.; Chan V.; Dean S.; Hubbard A.; Iotti R.; Jarboe T.; Lindl J.; Logan B.G.; et al. A plan for the development of fusion energy (Final Report to FESAC). 2003. Available online: http://fire.pppl.gov/fesac_dev_path_wksp.htm (Accessed on 30 April 2010).

66. European council of ministers conclusions of the fusion fast track experts meeting on the initiative of Mr. De Donnea (President of the Research Council), EUR (02) CCE-FU/FTC 10/4.1.1, Brussels, Belgium, 2001. (commonly called the "King Report"). 
67. Advisory Committee on Nuclear Fusion. National policy of future nuclear fusion research and development, 2005. Atomic Energy Commission. Available online: http:/www.aec.go.jp/jicst/NC /senmon/kakuyugo2/siryo/kettei/houkoku051026_e/index.htm (Accessed on 30 April 2010).

68. Kwon, M.; Na, Y.S.; Han, J.H.; Cho, S.; Lee, H.; Yu, I.K., Hong, B.G.; Kim, Y.H.; Park, S.R.; Seo, H.T. A strategic plan of Korea for developing fusion energy beyond ITER. Fusion Eng. Des. 2008, $83,883-888$.

69. El-Guebaly, L.A. 40 years of power plant studies: Brief historical overview and future trends. In Proceedings of $3^{\text {rd }}$ IAEA Technical Meeting on First Generation of Fusion Power Plants: Design \& Technology, Vienna, Austria, 2009, to be published.

(C) 2010 by the authors; licensee MDPI, Basel, Switzerland. This article is an Open Access article distributed under the terms and conditions of the Creative Commons Attribution license (http://creativecommons.org/licenses/by/3.0/). 